\title{
WIRELESS ENERGY METER AND TRACING OF HOOKING
}

\author{
Arkadip Basu \\ Department of Computer Science and Engineering \\ University of Engineering and Management, Kolkata, West Bengal, India
}

\begin{abstract}
Wireless Energy Meter is a modified form of traditional meter box which is useful for both consumers and suppliers as it will be cost efficient and help to trace hooking.
\end{abstract}

\section{Keywords - WEM, Hooking, Traditional}

\section{INTRODUCTION}

Electric utilities use electric meters installed at customers' premises to measure electric energy delivered to their customers for billing purposes. They are typically calibrated in billing units, the most common one being the Kilowatt hour $[k W h]$. They are usually read once each billing period. The traditional energy meter is unable to provide a fast and cost efficient service to the suppliers of the electrical energy. It is unable to detect the hooking made in the supply line as well as from the consumers. Our new energy meter will comprise both of both the system which are mentioned as the disadvantages of traditional meter box

\section{MATERIAL AND METHOD}

\section{Proposed Functioning of the Meter:}

The Meter which we are going to prepare would contain a system as like Mobile Phone. As like Mobile Phone the Meter Reading will be stored in each change in value to a permanent memory in a server to be situated in the Electricity Supply Agency. The said server will convert each change of consumed unit of electricity into money and this process may be installed for pre paid as well as post maid mode. The Electricity company will create a system in the Mobile Phone i.e App through which the consumer can see easily the consumed quantity of Electricity as well as the amount he has expended in a specified period. The Electricity supply company will have a profit in a manner that the company need not provide manpower to note down the Meter reading in every month which is sometimes a troublesome mechanism and huge manpower requires to be engaged for collecting DATA from the consumers Meters which are situated in a large area in a scattered manner. Besides that the Electricity Company can easily assess the quantity of Electricity unit that is stolen illegally from the electricity line by different means. The Electricity Company can easily monitor the said stolen part of electricity at every moment and can take immediate step to stop such kind of illegal act. The company will be able to reduce the cost of transmission as well as the amount of expenditure towards payment of wages to the employees who are employed in collecting Reading from the consumers Meter. The entire process will be through a wireless system and some programming is to be installed in the Meter in order to transmit DATA from the Meter to the Company's Server. Now we have to conduct a research as to whether the present Meters can be used by installing a procedure which can calculate each change of electricity consumption unit and send the said data to the company's server. We also have to make a thorough study towards feasibility of the said system.

\section{Tracing of Hooking from Domestic meter:}

Our modified meter box will contain a mobile like system which will detect the daily based electric unit consumed; just like mobile phone and it will send the data to the electricity board as stated earlier. Now as soon as extra electricity is consumed it will detect the extra unit and send a notification to the consumer via sms . Now the consumer can complain to the electricity board. For this we are planning to install a system which will monitor the electricity consumed and a graph will produced inside the meter and as soon as there is a rise of curve due to extra electricity consumption the system will be alert and send a sms or the consumer may check it from the app. Even we can add a feature in our said meter box which will store the amount of electricity that an electric gadget consumes. That will be even helpful for the consumer to understand what kind of appliance is connected from his or her meter.

\section{Tracing of Hooking from Supply line}

Hooking from electricity supply line is very common feature. To detect the hooking we are proposing an idea. We will introduce a location system. Now the meter box will keep 


\section{International Journal of Engineering Applied Sciences and Technology, 2019 Vol. 4, Issue 6, ISSN No. 2455-2143, Pages 120-121 \\ Published Online October 2019 in IJEAST (http://www.ijeast.com)}

a record of the electricity supplied. If there is any unusual increase of electric supply unless the electricity board has increases the load, through the location system easily the hooking can be traced out. This process, after that apply the inverse wavelet transform to the image for find out watermark image.

\section{ADVANTAGES}

[1] The Consumer can readily use his consumed units for a specific period and the amount of bill and thereby the consumer can easily increase or decrease his/her consumption.

[2] The said meter box and the system can maintain clarity between consumers and suppliers.

[3] At the end of the month the bill will be generated automatically so the suppliers of electricity need not require to check the units consumed as they used to do earlier.

[4] The electric energy suppliers can easily detect the hooking. The consumers can even trace the hooking from their houses.

\section{RESULT}

The energy meter said here and this system when introduced will be helpful to consumers and Suppliers in a great way. Now they don't have to depend till the end of month to check their consumptions. On the other hand it will reduce work load of the suppliers and help them to identify tracing. The whole system will be automatic and will benefit mankind.

\section{V.CONCLUSION}

Wireless Energy meter system will lead to significant changes in the near future. This adopted system will provide fast, efficient and error free working. This paper describes the overviews of different technologies used for overcoming the problems and at last come up to this level. New technologies and methodologies which are already used to improve have been discussed in this paper. The illegal hooking can easily be traced and will benefit both domestic and commercial side both in terms of money and energy. This paper will open the doors for future improvement and transformation of energy calculation methods.

\section{ACKNOWLEDGEMENT}

This work has been done by me with the help of my University. My father and mother has provided me with immense help throughout the work. Thus, I am thankful to all of them.

\section{REFERENCE}

[1] Mazidi A Muhammad, Mazidi Gillispie Janice and McKinlay D Rolin, (2006), "The 8051 Microcontroller and Embedded

Systems", Prentice Hall, Edition 2, 2006.

[2] Petroutsos, Evangelos (2008), "Mastering Microsoft Visual Basic2008", Wiley India, Edition 1, 2008.

[3] Roy Sukanya (2019)," A to Z of DBMS \& SQL", BlueRose, Edition 1

[4] Barr, Massa Antony(2006), Programming Embedded Systems, second edition, O'Reilly, 2006.

[5] A Athulya (2011) "Design and Development of a user friendly embedded product for testing serial communication interfaces", IJCA Proceedings on International conference on VLSI, Communication and Instrumentation (ICVCI)(10)"'35-37

[6] Derenzo E. S (2003), Practical Interfacing in the Laboratory: Using a PC for Instrumentation, Data Analysis and Control, Cambridge.

[7] Ghatak P. K, De Debasish (2017), Basic Electronics, Pearson

[8]] Banks J, Carson II S.J, Nelson L.B, and Nicol M.D,(2001) Discrete-Event System Simulation by, Prentice-Hall,

[9] V Prasanth (2012), Design and Implementation of Wireless Energy Meter System for Monitoring the SinglePhase supply, International Journal of Computer Applications (0975 - 8887), Volume 41- No.2, March 2012

[10] Preethi V, Harish G (2016), Design and implementation of smart energy meter, International Conference on Inventive Computation Technologies,2016

[11] Thakur T, Agnihotri Gayatri and Ahirwar Chaturbhuj (2002), Modernization of Metering, Billing and Collection System, the Customer Relationship Management, INDIAN INSTITUTE OF TECHNOLOGY, KHARAGPUR 721302, DECEMBER 27-29, 2002

[12] Mathur S (2011), Microprocessor 8086: Architecture, Programming and Interfacing, PHI Learning Private Limited, 2011. - Intel 8086 microprocessor resource

[13] Patterson D and Hennessy J (2009), Computer Organisation and Design: The Hardware/Software Interface, Morgan Kaufman, 4th Edition, 2009. - Lots of processor concepts and MIPS examples

[14] Sawarkar B ,Golait Snehal (2015), A Review Paper on Automatic Meter Reading and Instant Billing, International Journal of Advanced Research in Computer and Communication Engineering Vol. 4, Issue 1, January 2015 